\title{
Increasing the Sustainability of Pasta Production through a Life Cycle Assessment Approach
}

\author{
Luca Ruini ${ }^{1, *}$, Emilio Ferrari ${ }^{1}$, Pierluigi Meriggi ${ }^{2}$, \\ Massimo Marino ${ }^{3}$, and Filippo Sessa ${ }^{3}$ \\ ${ }^{1}$ Barilla G.e R. Fratelli S.p.A., Parma, Italy \\ \{luca.ruini, emilio.ferrari\} @barilla.com \\ ${ }^{2}$ Horta Srl, Piacenza, Italy \\ p.meriggi@horta-srl.com \\ ${ }^{3}$ Life Cycle Engineering, Turin, Italy \\ \{marino, sessa\} astudiolce.it
}

\begin{abstract}
Barilla put forth a project to increase the use of cereal sustainable cropping systems. The first part of the project was focused on identifying potential improvements in the most diffused cropping systems for the cultivation of Durum wheat in Italy, while maintaining high levels of quality and food safety standards. Results show that the well-known low input agronomic practices are environmentally friendly and also often economically advantageous. Implementation of dicotyledons into a cereal-only rotation allows a reduction of environmental impacts (- $36 \% \mathrm{GHG})$, a reduction of DON risk and an increase in net income for farmers (up to 31\%). In the second part Barilla gave to 13 farmers a decision support system (DSS) to help them in reducing production costs and environmental impacts. Results show that the only adoption of DSS contributes in reducing carbon footprint (-10\%), and costs for pesticides and fertilizers $(-10 \%)$.
\end{abstract}

Keywords: Life cycle assessment, LCA, Food, Pasta, Durum wheat.

\section{Introduction}

Considering that many studies revealed that the agricultural phase of food products have a relatively high environmental impacts, a specific study was conducted to determine whether different crop rotations could aid in increasing sustainability of the whole process (Caporali et al., 1992).

As it's shown in the figure 1, Barilla has released its study on the environmental impacts of pasta conducted with the life cycle assessment methodology through the publication of the Environmental Product Declaration (Barilla, 2010).

Durum wheat cultivation is responsible for more than $80 \%$ of the ecological footprint and for entirety of the water footprint and it has the same carbon footprint impact of the home cooking phase. Due to this reason, Barilla put forth a specific project aimed to increase widespread use of sustainable cropping systems of durum

\footnotetext{
* Corresponding author.
} 
wheat. Analysis was based on a holistic approach, taking into consideration economic, agronomic, food safety and environmental indicators. The project focused on identifying potential improvements of the most diffused cropping systems for the cultivation of Durum wheat, while maintaining high levels of quality and health standards.

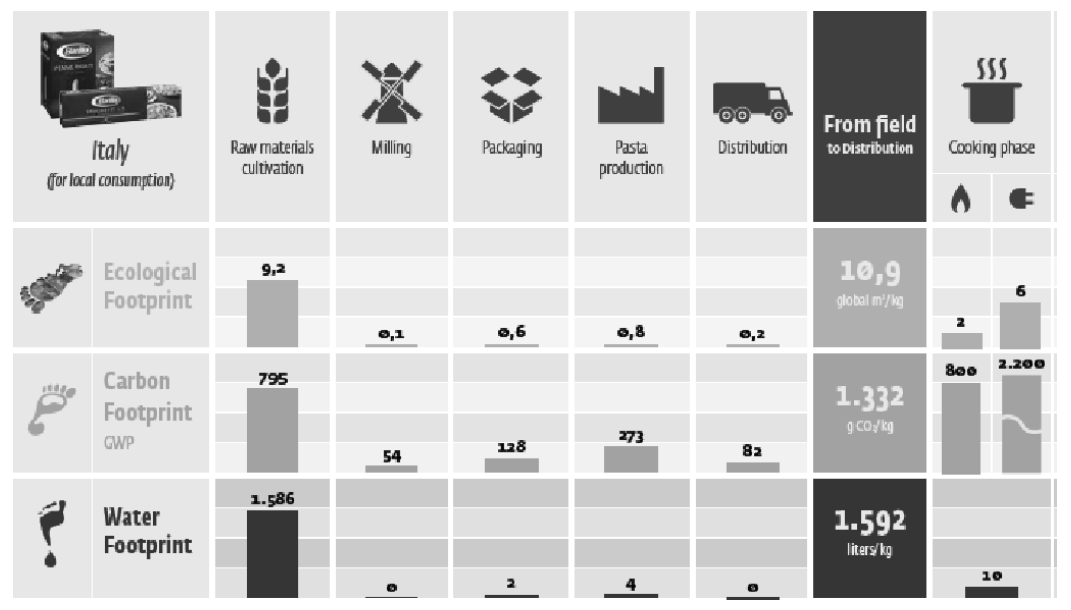

Fig. 1. Ecological, Carbon and Water footprint of Barilla's pasta produced in Italy , (Barilla, 2010)

\section{Research Background}

Italy was the first cultivation area considered because it is the country where Barilla purchases more than $60 \%$ of the durum wheat necessary to its entire pasta production.

The project started in 2010 and it has been developed in different phases.

In the first years the Company put in place theoretical studies on durum wheat cultivation in Italy and the evaluation of environmental impacts and of overall agriculture efficiency through the use of economic, social and environmental sustainability indicators.

In 2010-2011 Barilla analysed a sample of farm to compare real data from farms with optimal values to obtain sustainable productions. The results shows that rotation of durum wheat with dicotyledons is more sustainable than rotations only with cereals and monoculture, and a reduction in production costs is possible with a better efficiency in the use of inputs. The results of this study were published in the Handbook for sustainable cultivation of quality durum wheat in Italy, which serves as source of practical suggestions for farmers. Horta S.r.l, one of the partner of this project, has subsequently developed the decision support system (DSS) granoduro.net ${ }^{\mathrm{TM}}$, a web service that integrates information on weather patterns, soil conditions and varietal characteristics to provide famers decision support related to 
seeding, weeds control, nitrogen fertilization and information about risk for fungal diseases (yellow and brown rust, septoria, powdery mildew, fusarium head blight and related mycotoxin).

Finally, in 2011-2012 the project was extended to about 15 farms to demonstrate that an accurate planning of crop rotations and the use of a decision support system as granoduro.net could help in being more sustainable, both environmentally and economically. In this part of the project the DSS was given to the farmers to help them following the suggestions of the Handbook for the sustainable cultivation of quality durum wheat in Italy.

The "sustainable durum wheat" project is going on. In 2012-2013 the sample involved in the last crop year will be supplemented with new farms (around 100) situated in initially not considered areas.

\section{Methods}

With the improvement project in focus, analysis of durum wheat cultivation was performed by identifying the main durum wheat cropping systems. The cropping systems considered were four-year rotations in which the cultivation of different crops was planned. Durum wheat cultivation in Italy was relegated to four main areas: Northern Italy (Lombardy-Veneto area and Emilia Romagna), Central Italy (Tuscany, Umbria and Marche) and Southern Italy (Apulia and Sicily).

Tables 1, 2, 3 and 4 list the crop rotations identified in those four main areas.

Table 1. Crop rotations of the Lombardy-Veneto plain

\begin{tabular}{|c|l|l|l|l|}
\hline $\begin{array}{l}\text { Crop } \\
\text { rotation }\end{array}$ & \multicolumn{1}{|c|}{ Year 1 } & \multicolumn{1}{|c|}{ Year 2 } & \multicolumn{1}{c|}{ Year 3 } & \multicolumn{1}{|c|}{ Year 4 } \\
\hline $\mathbf{1}^{*}$ & maize & durum wheat & maize & maize \\
\hline $\mathbf{2}$ & soybean & durum wheat & rapeseed & maize \\
\hline
\end{tabular}

*most common scenario.

Table 2. Crop rotations of Emilia Romagna

\begin{tabular}{|c|l|l|l|l|}
\hline $\begin{array}{l}\text { Crop } \\
\text { rotation }\end{array}$ & \multicolumn{1}{|c|}{ Year 1 } & \multicolumn{1}{|c|}{ Year 2 } & \multicolumn{1}{c|}{ Year 3 } & \multicolumn{1}{c|}{ Year 4 } \\
\hline $\mathbf{1}^{*}$ & maize & durum wheat & sorghum & soft wheat \\
\hline $\mathbf{2}$ & soybean & durum wheat & maize & soft wheat \\
\hline $\mathbf{3}$ & tomato & durum wheat & maize & soft wheat \\
\hline
\end{tabular}

*most common scenario. 
Table 3. Crop rotations of Central Italy

\begin{tabular}{|c|l|l|l|l|}
\hline $\begin{array}{l}\text { Crop } \\
\text { rotation }\end{array}$ & \multicolumn{1}{|c|}{ Year 1 } & \multicolumn{1}{|c|}{ Year 2 } & \multicolumn{1}{c|}{ Year 3 } & \multicolumn{1}{c|}{ Year 4 } \\
\hline $\mathbf{1}^{*}$ & durum wheat & durum wheat & sorghum & durum wheat \\
\hline $\mathbf{2}$ & proteic pea & durum wheat & proteic pea & durum wheat \\
\hline $\mathbf{3}$ & alfalfa & alfalfa & alfalfa & durum wheat \\
\hline $\mathbf{4}$ & sunflower & durum wheat & rapeseed & durum wheat \\
\hline
\end{tabular}

*most common scenario.

Table 4. Crop rotations of Southern Italy

\begin{tabular}{|c|l|l|l|l|}
\hline $\begin{array}{l}\text { Crop } \\
\text { rotation }\end{array}$ & \multicolumn{1}{|c|}{ Year 1 } & \multicolumn{1}{c|}{ Year 2 } & Year 3 & Year 4 \\
\hline $\mathbf{1}^{*}$ & durum wheat & durum wheat & durum wheat & durum wheat \\
\hline $\mathbf{2}$ & fodder & durum wheat & fodder & durum wheat \\
\hline
\end{tabular}

Then, Barilla compared two different durum wheat crop management. The first one consists in farmer's usual crop management with only farmer crop choices and strategies, while in the second one the farmers were supported by the handbook and the DSS granoduro.net ${ }^{\mathrm{TM}}$. The test was conducted in 13 farms, located in the most important areal for durum wheat cultivation in Italy. In order to verify the effectiveness and feasibility of the suggested practices, farmers have agreed to cultivate part of their land following the handbook and granoduro.net and part following their routine practices.

\subsection{Measures}

The indicators used to quantify the different cropping system impacts were divided into environmental indicators (carbon footprint, water footprint and ecological footprint), agronomic indicators (NUE), food safety indicators (DON index) and economic indicators (Net income).

Carbon footprint, also known as "global warming potential" (GWP), expresses the total amount of greenhouse gases (GHG) produced to the system and it's usually expressed in $\mathrm{kg}$ of $\mathrm{CO} 2$-equivalent. It is regulated at an international level by the documents Greenhouse gas protocol (World Resource Institute, 2010) and PAS 2050 (British Standard Institute, 2011). Concerning the Carbon footprint of products an ISO regulation is under development.

Water footprint measures the water consumption of a system in terms of volume of water evapotranspirated by plants, consumed or polluted. It is regulated by the document "The water footprint assessment manual" (Hoekstra et al, 2011). Data about the water footprint of the main crops cultivated in the world are reported in the database of Mekonnen (2010). 
Ecological footprint is a measure of how much biologically productive land and water surface an activity requires to produce all the resources it consumes and to absorb the waste it generates. It is measured in global hectares (gha) and it is regulated by the document "Calculation methodology for the national Footprint accounts" (Ewing et al., 2010).

NUE is the Nitrogen Use Efficiency: it is measured in terms of $\mathrm{kg}$ or product per $\mathrm{kg}$ of nitrogen given to the crop through fertilization (Rahimizadeh, 2010).

The DON Index expresses the risk of molecules toxic to human health originated by the proliferation of pathogenic fungi Fusarium Head Blight (FHB), producers of secondary metabolites called mycotoxins. These mycotoxins can be present in different quantities of crop yields obtained. It depends on the choices made and on the seasonal cultivation during the crop cycle. The development of these fungi depends on meteorological factors, along with specific factors linked with production unit, such as varietal susceptibility, the rotation of crops and the tillage of soil. DON content in wheat for human consumption is limited by law. The DON index is calculated on a scale of 0 to 9 where 0 is a risk-free condition and 9 is that of highest risk (Ruini et al., 2011). This one is related to law limit. For unprocessed durum wheat the limit is $1750 \mathrm{ppb}$ of deoxynivalenol contamination. High DON risk means high probability to overcome the law limit. Regions of Northern Italy have meteorological conditions more favourable to the onset of DON.

Net Income is the difference between direct costs of cultivation (in field activities and technical tools) and the gross marketable production. This profitability indicator refers to March 2011 quotation for medium quality durum wheat in Italian commodity exchange (280-290 €/ton).

Agricultural practices can influence the environmental, economic and food safety performances of cultivation (Tilman et al, 2002). In particular, this study contemplates the main practices of crop rotation, use of fertilizers, tillage, seeding, and weed and pest management.

\section{Results}

The study shows that in the Lombardy-Veneto area, where agriculture is considered advanced for a technological and knowledge standpoint, rotation 2 (durum wheat after soybean) performed better than rotation 1 (durum wheat after maize) with regard to all the indicators (Table 5). Aversion of maize as precession for durum wheat allows considerable reduction of the DON risk index.

In Emilia Romagna (Table 6) rotation 1 (cereal based) yielded high DON risk due to maize as precession for durum wheat, while having lowest NUE among the rotations considered. The low efficiency in nitrogen utilization has as consequence higher values of carbon footprint.

In central Italy (table 7) durum wheat cultivation has the lowest environmental impact for rotation 2 (fodder). The net income in such rotation is however lower the rotations 3 and 4 . Rotation 1, with 3 years of durum wheat and 1 year of sorghum produced the highest environmental impacts and DON risk with the lowest yield and net income. 
In southern Italy (table 8) rotation with four years of durum wheat was the poorest in all indicators.

Table 5. Indicators calculated in the Lombardy-Veneto area

\begin{tabular}{|c|c|c|c|c|c|c|c|}
\hline $\begin{array}{c}\text { Crop } \\
\text { rotation }\end{array}$ & Yield & $\begin{array}{c}\text { Carbon } \\
\text { footprint }\end{array}$ & $\begin{array}{c}\text { Water } \\
\text { footprint }\end{array}$ & $\begin{array}{c}\text { Ecological } \\
\text { footprint }\end{array}$ & $\begin{array}{c}\text { Net } \\
\text { Income }\end{array}$ & NUE & $\begin{array}{c}\text { DON } \\
\text { risk }\end{array}$ \\
\hline $\mathrm{t} / \mathrm{ha}$ & $\begin{array}{c}\mathrm{t} \text { of } \mathrm{CO}_{2^{-}} \\
\text {eq/t of } \mathrm{d} . \\
\text { wheat }\end{array}$ & $\begin{array}{c}\mathrm{t} \text { of } \\
\text { water/t of } \\
\mathrm{d} \text {. wheat }\end{array}$ & $\begin{array}{c}\text { global ha/t } \\
\text { of d. wheat }\end{array}$ & $\begin{array}{c}€ / \mathrm{t} \text { of d. } \\
\text { wheat }\end{array}$ & $\begin{array}{c}\mathrm{kg} \text { of d. } \\
\text { wheat/kg } \\
\text { of N }\end{array}$ & - \\
\hline 1 & 7.0 & 0.51 & 315 & 0.38 & 155 & 33.8 & 7.9 \\
\hline 2 & 7.5 & 0.42 & 294 & 0.36 & 167 & 44 & 1.7 \\
\hline
\end{tabular}

Table 6. Indicators calculated in Emilia Romagna

\begin{tabular}{|c|c|c|c|c|c|c|c|}
\hline $\begin{array}{c}\text { Crop } \\
\text { rotation }\end{array}$ & $\begin{array}{c}\text { Yield } \\
\text { (t/ha) }\end{array}$ & $\begin{array}{c}\text { Carbon } \\
\text { footprint }\end{array}$ & $\begin{array}{c}\text { Water } \\
\text { footprint }\end{array}$ & $\begin{array}{c}\text { Ecological } \\
\text { footprint }\end{array}$ & $\begin{array}{c}\text { Net } \\
\text { Income }\end{array}$ & NUE & $\begin{array}{c}\text { DON } \\
\text { risk }\end{array}$ \\
\hline $\mathrm{t} / \mathrm{ha}$ & $\begin{array}{c}\mathrm{t} \text { of } \mathrm{CO}_{2^{-}} \\
\text {eq/t of d. } \\
\text { wheat }\end{array}$ & $\begin{array}{c}\mathrm{t} \text { of } \\
\text { water/t of } \\
\text { d. wheat }\end{array}$ & $\begin{array}{c}\text { global ha/t } \\
\text { of d. wheat }\end{array}$ & $\begin{array}{c}€ / \mathrm{t} \text { of d. } \\
\text { wheat }\end{array}$ & $\begin{array}{c}\mathrm{kg} \text { of d. } \\
\text { wheat/kg } \\
\text { of } \mathrm{N}\end{array}$ & - \\
\hline 1 & 7.3 & 0.51 & 328 & 0.40 & 141 & 32.5 & 7.9 \\
\hline 2 & 7.5 & 0.41 & 315 & 0.38 & 157 & 42.2 & 2.3 \\
\hline 3 & 7.5 & 0.36 & 315 & 0.38 & 151 & 47.1 & 1.7 \\
\hline
\end{tabular}

Table 7. Indicators calculated in central Italy

\begin{tabular}{|c|c|c|c|c|c|c|c|}
\hline $\begin{array}{c}\text { Crop } \\
\text { rotation }\end{array}$ & $\begin{array}{c}\text { Yield } \\
\text { (t/ha) }\end{array}$ & $\begin{array}{c}\text { Carbon } \\
\text { footprint }\end{array}$ & $\begin{array}{c}\text { Water } \\
\text { footprint }\end{array}$ & $\begin{array}{c}\text { Ecological } \\
\text { footprint }\end{array}$ & $\begin{array}{c}\text { Net } \\
\text { Income }\end{array}$ & NUE & $\begin{array}{c}\text { DON } \\
\text { risk }\end{array}$ \\
\hline $\mathrm{t} / \mathrm{ha}$ & $\begin{array}{c}\mathrm{t} \text { of } \mathrm{CO}_{2^{-}} \\
\text {eq/t of d. } \\
\text { wheat }\end{array}$ & $\begin{array}{c}\mathrm{t} \text { of } \\
\text { water/t of } \\
\text { d. wheat }\end{array}$ & $\begin{array}{c}\text { global ha/t } \\
\text { of d. wheat }\end{array}$ & $\begin{array}{c}€ / \mathrm{t} \text { of d. } \\
\text { wheat }\end{array}$ & $\begin{array}{c}\mathrm{kg} \text { of d. } \\
\text { wheat/kg } \\
\text { of N }\end{array}$ & - \\
\hline 1 & 3.3 & 0.67 & 745 & 0.73 & 24.1 & 28.4 & 3.9 \\
\hline 2 & 4.3 & 0.30 & 478 & 0.47 & 99.4 & 66.7 & 0 \\
\hline 3 & 5.3 & 0.43 & 502 & 0.49 & 139 & 45.3 & 0 \\
\hline 4 & 5.3 & 0.34 & 479 & 0.47 & 139 & 58.5 & 0 \\
\hline
\end{tabular}

Table 8. Indicators calculated in southern Italy

\begin{tabular}{|c|c|c|c|c|c|c|c|}
\hline $\begin{array}{c}\text { Crop } \\
\text { rotation }\end{array}$ & $\begin{array}{c}\text { Yield } \\
\text { (t/ha) }\end{array}$ & $\begin{array}{c}\text { Carbon } \\
\text { footprint }\end{array}$ & $\begin{array}{c}\text { Water } \\
\text { footprint }\end{array}$ & $\begin{array}{c}\text { Ecological } \\
\text { footprint }\end{array}$ & $\begin{array}{c}\text { Net } \\
\text { Income }\end{array}$ & NUE & $\begin{array}{c}\text { DON } \\
\text { risk }\end{array}$ \\
\hline & $\mathrm{t} / \mathrm{ha}$ & $\begin{array}{c}\mathrm{t} \text { of } \mathrm{CO}_{2^{-}} \\
\text {eq/t of d. } \\
\text { wheat }\end{array}$ & $\begin{array}{c}\mathrm{t} \text { of } \\
\text { water/t of } \\
\text { d. wheat }\end{array}$ & $\begin{array}{c}\text { global ha/t } \\
\text { of d. wheat }\end{array}$ & $\begin{array}{c}€ / \mathrm{t} \text { of d. } \\
\text { wheat }\end{array}$ & $\begin{array}{c}\mathrm{kg} \text { of d. } \\
\text { wheat/kg } \\
\text { of N }\end{array}$ & - \\
\hline 1 & 2.5 & 0.74 & 1429 & 1.11 & 23.3 & 32.4 & 1.1 \\
\hline 2 & 5.0 & 0.45 & 694 & 0.54 & 133 & 44.3 & 0 \\
\hline 3 & 4.2 & 0.53 & 874 & 0.68 & 112 & 38.7 & 0 \\
\hline 4 & 5.0 & 0.45 & 694 & 0.54 & 133 & 44.3 & 0 \\
\hline
\end{tabular}


Then, 13 farms were involved in the study. The cultivation of durum wheat after several crops was tested. Such previous crops were divided into four groups as shown in table 9 (cereals, industrial crops, leguminous, vegetables). A comparison of the durum wheat cultivated after those crops was made.

Table 9. Crops that forego the durum wheat cultivation

\begin{tabular}{|c|c|c|c|}
\hline Cereal & $\begin{array}{c}\text { Industrial } \\
\text { crops }\end{array}$ & Leguminous & Vegetables \\
\hline Maize & Sunflower & Faba bean & Tomato \\
\hline Sorghum & Rape seed & Chickpea & \\
\hline Soft Wheat & Sugar beet & Proteic pea & \\
\hline Durum Wheat & & & \\
\hline
\end{tabular}

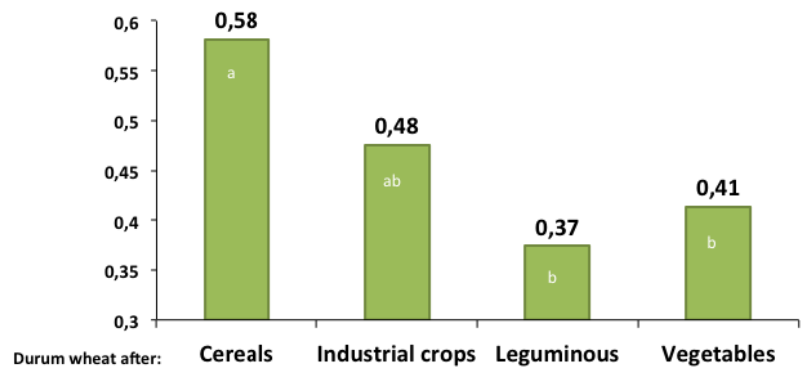

Fig. 2. Carbon Footprint (t CO2/t durum wheat) and previous crop

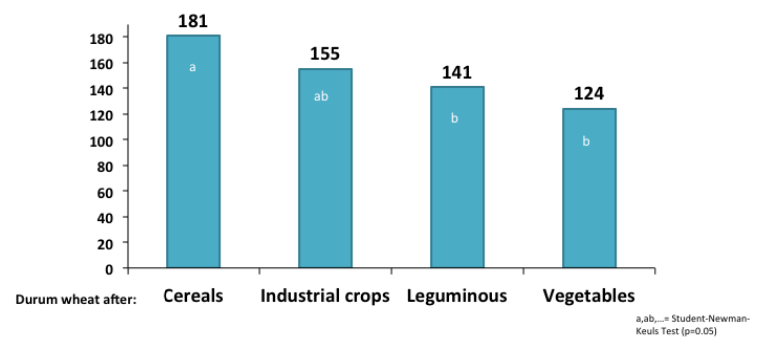

Fig. 3. Production costs (€/ t durum wheat) and previous crop

The results are encouraging. A favourable previous crop contributes in reducing significantly the greenhouse gas emissions (- $36 \%$ equivalent to $-0,21 \mathrm{t} \mathrm{CO} 2-\mathrm{eq} / \mathrm{t}$ grain) compared to an unfavourable one (see fig.2). Concerning the expenses it contribute in reducing significantly production costs $(-31 \%$ equivalent to $-57 € / t)$ compared to an unfavourable one (fig.3). To finish, as it's shown in fig.4, a 
favourable previous crop contributes in obtaining a significantly higher yield $(+20 \%$ equivalent to $+1,3 \mathrm{t} / \mathrm{ha}$ ) compared to an unfavourable one.

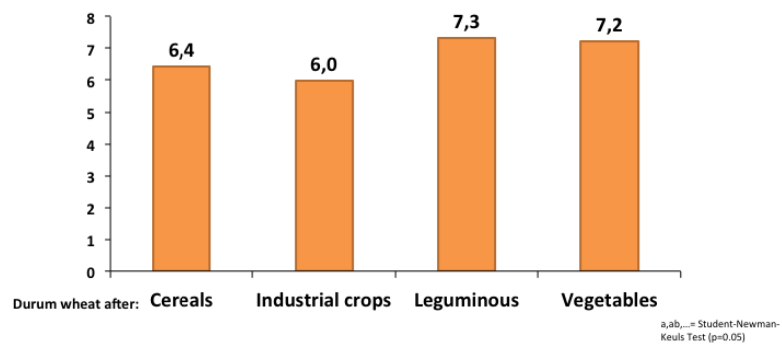

Fig. 4. Yeld (t durum wheat/ha) and previous crop

Previous crops were then divided into three groups (favourable, neutral and unfavourable) according to their influence on durum wheat cultivation (table 10). A comparison was made, for each type of previous crop, between the cultivation of durum wheat with and without the use of the decision support system granoduro.net $^{\mathrm{TM}}$.

Table 10. Groups of previous crops

\begin{tabular}{|c|c|}
\hline \multirow{4}{*}{ Favourable } & Faba bean \\
\cline { 2 - 2 } & Chickpea \\
\cline { 2 - 2 } & Rape seed \\
\cline { 2 - 2 } Neutral & Proteic pea \\
\cline { 2 - 2 } Unfavourable & Sugar beet \\
\hline \multirow{2}{*}{ Unflower } \\
\cline { 2 - 2 } & Sorghum \\
\cline { 2 - 2 } & Wheat \\
\hline
\end{tabular}

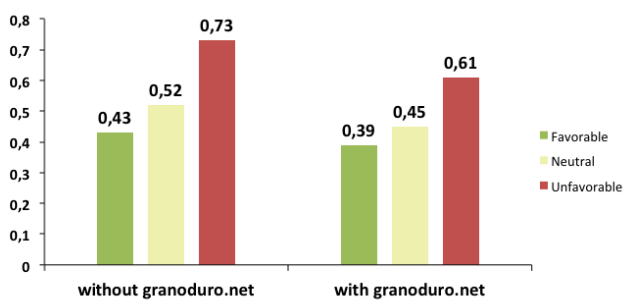

Fig. 5. Carbon footprint (t CO2/ $\mathrm{t}$ durum wheat) and granoduro.net 
Results show that the use of granoduro.net contribute in reducing carbon footprint (-10\%, fig. 5), supply to the reduction of production costs especially in case of favourable or neutral previous crop (- 10\%, fig. 6) and contributes in reducing the costs of pesticides and fertilizers management (fig.7).

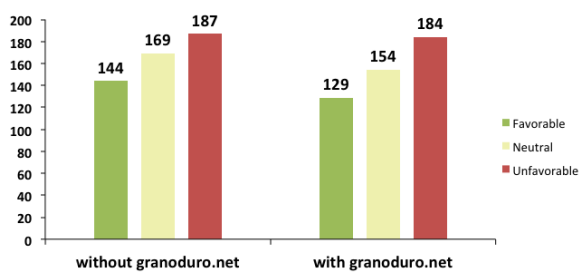

Fig. 6. Production costs (€/ $t$ durum wheat) and granoduro.net

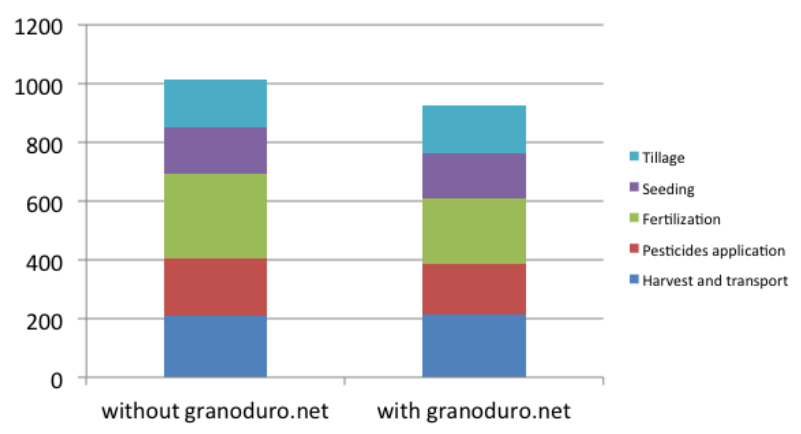

Fig. 7. Production costs (€/ ha) and granoduro.net

To sum up the use of granoduro.net ${ }^{\mathrm{TM}}$ contribute to a reduction in direct costs of production $(-10 \%=-15 € /$ ton $)$, a reduction in Carbon footprint $(-10 \% \mathrm{CO} 2=-0,12$ ton $\mathrm{CO} 2 /$ ton), an increasing in nitrogen use efficiency and to maintain high yields.

\section{Conclusions}

The project has demonstrated the importance of an integrated approach to study the sustainability of a cropping system. It's important to bear in mind that agriculture is primarily an economic activity and there's the risk walking the line of counterproductivity when merely focusing on environmental and food safety issues. However, the study shows that environmentally friendly practices are also often economically advantageous because they greatly increase the efficiency of technical tool usage and the yield (+1,3 t/ha). Implementation of dicotyledons into a cereal-only rotation allows a reduction of environmental impacts $(-0,21 \mathrm{t} \mathrm{CO} 2-\mathrm{eq} / \mathrm{t}$ grain), a reduction of DON risk and an increase in net income, thanks to the reduction of production costs $(-57 € / t)$. 
The project has also highlighted the importance of technical instruments such as the DSS granuduro.net to help the farmers in their decisions. With this kind of support the agriculture would be less costly $(-10 \%)$ and at the same time the environmental impacts linked to its activities could be reduced (-10\%).

The next steps of the project are to continue the undertaken experimentations and to take "sustainable agriculture" to a large scale by signing in the next years an increasing number of contracts with farmers that encompass sustainable practices.

\section{References}

1. Barilla, Environmental Product Declaration of Dry semolina pasta from durum wheat (2010), http: / / www . environdec.com/en/Detail/?Epd=7699 (last accessed March 2012)

2. British Standard Institute, PAS 2050:2011. Specification for the assessment of the life cycle greenhouse gas emissions of goods and services, London, UK (2011)

3. Caporali, F., Onnis, A.: Validity of rotation as an effective agroecological principle for a sustainable agriculture. Agriculture, Ecosystems \& Environment 41(2), 101-113 (1992)

4. Ewing, B., Reed, A., Galli, A., Kitzes, J., Wackernagel, M.: Calculation Methodology for the National Footprint Accounts, 2010th edn. Global Footprint, Oakland (2010)

5. Hoekstra, A.Y., Chapagain, A.K., Aldaya, M.M., Mekonnen, M.M.: The water footprint assessment manual: Setting the global standard, Earthscan, London, UK (2011)

6. Mekonnen, M.M., Hoekstra, A.Y.: The green, blue and grey water footprint of crops and derived crop products, Value of Water Research Report Series No. 47, UNESCO-IHE, Delft, The Netherlands (2010), http://www.waterfootprint.org/Reports/ Report47WaterFootprintCrops-Vol1.pdf

7. Rahimizadeh, M., Kashani, A., Feizabadi, A.Z., Koocheki, A.R., Mahallati, M.N.: Nitrogen use efficiency of wheat as affected by preceding crop, application rate of nitrogen and crop residues. Australian Journal of Crop Science 4(5), 363-368 (2010)

8. Ruini, L., Ferrari, E., Meriggi, P., Marino, M., Boeri, F., Ruggeri, M.: Sostenibilità dei sistemi colturali con frumento duro. Filiera grano duro news (April 18, 2011)

9. Tilman, D., Cassman, K.G., Matson, P.A., Naylor, R., Polasky, S.: Agricultural sustainability and intensive production practices. Nature 418, 671-677 (2002)

10. World Resources Institute, The Greenhouse Protocol - Product Life Cycle Accounting and Reporting Standard (2010) 